Check for updates

Cite this: Mater. Adv., 2021, 2,4380

Received 3rd March 2021 Accepted 7th May 2021

DOI: 10.1039/d1ma00184a

rsc.li/materials-advances

\section{Promoting the neural differentiation of embryonic stem cells by using thermosensitive nanocomposites $\dagger$}

\author{
Shaoyu Cheng, Fei Yu, Benben Lu, Hongwei Wang* and Lin Yuan (D) *
}

\begin{abstract}
Nerve cells differentiated from embryonic stem cells (ESCs) play an important role in the treatment of neurodegenerative diseases. Heparin has great potential for inducing ESCs to differentiate into nerve cells, but due to the shortcomings of heparin itself, its effect on inducing differentiation of ESCs is limited. In this study, the thermosensitive copolymer pNIPAAm-b-p(MAG-co-SPA) (pNMS) was synthesized with $\mathrm{N}$-isopropylacrylamide (NIPAAm) as monomer and heparin mimic $\mathrm{p}$ (MAG-CO-SPA) (pMS) as macromolecular chain transfer agent. Considering the biocompatibility of AuNPs, the nanocomposites were prepared, and their effects on inducing differentiation of ESCs were studied in detail. Compared to heparin, nanocomposites have a stronger effect on the differentiation of ESCS, especially AuNPs-pNMS, which can better promote the expression of $\beta 3$-tubulin and stimulate the synthesis of proteins required for neuronal maturation. The results show that AuNPs-pNMS has a stronger ability to induce differentiation than AuNPs-pMS due to the presence of the pNIPAAm segment. The synergistic effect of pNIPAAm and pMS in AuNPs-pNMS greatly increases the efficiency of nanocomposite binding to FGFR, further enhancing the effect of the neural differentiation of ESCs. The effect of AUNPs-pNMS in promoting the differentiation of ESCs is also related to the relative molecular weight of pNMS. Under the premise of controlling the relative molecular weight of pMS to be $8900 \mathrm{Da}$, when the molecular weight of pNMS is $28100 \mathrm{Da}$, AuNPs-pNMS has the strongest effect of promoting neural differentiation of ESCs. This thermosensitive nanocomposite provides a new strategy for promoting the neural differentiation of ESCs.
\end{abstract}

\section{Introduction}

Embryonic stem cells (ESCs) are totipotent cells with long-term self-reproduction ability and the potential to differentiate into almost all cell types in the body. ${ }^{1-3}$ In recent years, neurodegenerative diseases have threatened the safety and quality of life of human beings and therefore attracted social attention. These diseases are considered to be mainly caused by nerve cell damage or dysfunction. In the treatment of these diseases, nerve cell-based replacement therapy or transplantation has become a promising strategy to repair damaged nerve cells and restore their function. ${ }^{4-6}$ Under normal circumstances, ESCs can be induced to differentiate into specific cells or tissues through some biological, chemical, and physical treatments ${ }^{7-9}$

State and Local Joint Engineering Laboratory for Novel Functional Polymeric Materials, College of Chemistry, Chemical Engineering and Materials Science, Soochow University, Suzhou 215123, P. R. China. E-mail: wanghw@suda.edu.cn, yuanl@suda.edu.cn

$\dagger$ Electronic supplementary information (ESI) available. See DOI: 10.1039/ d1ma00184a when they are cultured in vitro. Differentiation of ESCs provides convenience for the treatment of neurodegenerative diseases.

There are many ways to induce stem cells to differentiate into nerve cells, such as adding exogenous growth factors, ${ }^{10,11}$ biologically active molecules, ${ }^{12}$ and chemical inducers, ${ }^{13}$ the application of electric and magnetic fields, ${ }^{14}$ etc. But exogenous growth factors, including nerve growth factor $(\mathrm{NGF})^{15}$ and fibroblast growth factor (FGF), ${ }^{16,17}$ are expensive, and their half-life is short, so their practical applications are greatly restricted. In addition, although chemical inducers can promote the differentiation of ESCs into nerve cells, ${ }^{18}$ their toxicity can also cause damage to cells, and affect cell selfproliferation and even lead to apoptosis. Physical stimulation, such as electrical stimulation or magnetic field stimulation, may cause some undesirable differentiation directions. In recent years, studies have shown that glycosaminoglycans (GAGs), especially heparin and its mimics, can promote the neural differentiation of ESCs. ${ }^{19-21}$

GAGs are a type of natural polysaccharide polymer with a complex structure and versatile applications. ${ }^{22,23}$ Most GAGs exist as proteoglycans on the cell membrane. Proteoglycans on 
the cell membrane do not have a considerable effect in promoting the neural differentiation of ESCs and may cause ESCs to differentiate into different germ layers. Previous studies have shown that heparin has a prominent role in promoting the differentiation of stem cells. A large number of sulfonic acid groups in its structure can bind to receptors on the stem cell membrane to promote differentiation. ${ }^{24-27}$ However, heparin can bind to different biologically active factors, thereby affecting the differentiation direction of ESCs. Therefore, heparin mimics containing sulfonic acid groups are the better choice to promote the differentiation of ESCs. ${ }^{12,19,21}$ Wang et al. proposed a unit reorganization strategy to synthesize a heparinmimicking polymer by using independent units with functional groups similar to natural heparin. ${ }^{19}$ Lei et al. used the unit reorganization strategy to synthesize heparin mimics containing different sulfonic acid units. Furthermore, the heparin mimic forms a heparin mimic-FGFR-FGF2 ternary complex on the cell membrane to promote the neural differentiation of ESCs. ${ }^{28}$ However, because it cannot precisely control the sequence of structural units in molecular weight, and the structural sequence of heparin has an important relationship with promoting the neural differentiation of ESCs, this strategy still has some shortcomings. According to reports, heparin mimics can bind to FGFR and FGF through the sulfonic acid groups on their chain, which promotes the formation of a stable heparin mimic-FGF2-FGFR ternary complex on the cell membrane. It can make FGFR form dimers and activate the formation of signalling pathways that promote the neural differentiation of ESCs. ${ }^{20}$ In this way, improving the binding ability of heparin mimics and FGFR is more conducive to promoting the neural differentiation of ESCs.

Liu et al. modified a phospholipid group at the end of the polymer and anchored it to the cell membrane, which increased the efficiency of heparin mimic binding to FGF2 and improved the effect in promoting the differentiation of ESCs. The behavior of heparin mimic in promoting the neural differentiation of ESCs has been studied in depth, and the structural composition of heparin itself has been relatively clear. On this basis, similar to Liu et al., modifying other functional groups or segments outside of the heparin structure has become the primary choice. In addition to the chemical properties of biological materials that promote the differentiation of ESCs, the physical properties of some biological materials can also assist or induce the differentiation of stem cells. Promoting the differentiation of ESCs through the synergistic effect of the chemical properties and physical properties of biological materials is a promising choice. Seo et al. used temperature-sensitive $\mathrm{p}$ (NIPAAm-co-Am) nanoparticles to assist the delivery of RA, thereby promoting the neural differentiation of stem cells. ${ }^{29,30}$ The two acted synergistically to improve the efficiency of differentiation. It can be seen that the temperature sensitivity of pNIPAAm has certain research significance for the neural differentiation of stem cells. Previous studies have shown that the dynamic presentation of nano-scale ligands can regulate the adhesion and differentiation of stem cells. Kang et al. used nanoswitches controlled by coordination to regulate the mechanosensing and differentiation of stem cells. $^{31}$ The high specific surface area of AuNPs could enable them to have a high carrier capacity for polymers. The good biocompatibility and good dispersion of AuNPs in solution help them contact well with the stem cell surface. So AuNPs were introduced in the design and they acted as excellent carriers which can support the good assembly of polymers to promote the neural differentiation of ESCs. ${ }^{32,33}$

Responsive polymers are polymers that can respond to external environmental stimuli (such as temperature, light, $\mathrm{pH}$, etc.) to trigger changes in their conformation. When a specific chemical or physical signal changes slightly, responsive polymers can produce a significant response. ${ }^{34}$ Temperature-sensitive polymers are the most widely used stimulus-responsive polymers. For temperaturesensitive polymers with a low critical solution temperature (LCST), when the ambient temperature is lower than the LCST, the hydrogen bond between the water molecule and the hydrophilic group on the polymer chain causes the polymer chain to form a stable hydration structure. The polymer chains exhibit hydrophilicity and exist in the form of extended coils. When the ambient temperature rises above the LCST, the hydrogen bond is broken and the hydration structure is destroyed. The polymers desolvate and collapse into a dense globular conformation, showing a hydrophobic state. ${ }^{35-37}$ pNIPAAm $(\mathrm{pN})$ is a typical temperaturesensitive polymer, with a LCST of around $32{ }^{\circ} \mathrm{C}$. In this study, the use of NIPAAm and heparin mimic block copolymerization was proposed to synthesize temperature-sensitive copolymers pNIPAAm- $b$-p(MAG-co-SPA) (pNMS). The AuNPs-pNMS was prepared to promote the neural differentiation of ESCs. Compared to $25{ }^{\circ} \mathrm{C}$, the hydrated diameter of AuNPs-pNMS decreased with the collapse of the pNIPAAm fragment at $37{ }^{\circ} \mathrm{C}$. The experimental results showed that AuNPs-pNMS had good temperature sensitivity. The polymer on the surface of AuNPs could specifically bind to the FGFR monomer on the cell membrane. In addition, AuNPs as carriers would be enriched on the cell membranes, which was more conducive to the combination of the polymer and FGFR monomer. At the same time, when the thermosensitive nanocomposites were exposed to a temperature of $37^{\circ} \mathrm{C}$, the polymer chain collapsed and the hydrated diameter of AuNPs-pNMS decreased, pulling the FGFR monomers, shortening the distance between the monomers, and promoting the formation of FGFR dimers. In addition, the FGFR dimer was formed, which activated the signalling pathway of the neural differentiation of ESCs (Scheme 1). This study provides a new strategy for promoting the neural differentiation of ESCs, which has important biological significance and practical application value.

\section{Experimental}

\subsection{Materials}

2,2-Azobis-(isobutyronitrile) (AIBN) and D-glucosamine hydrochloride were purchased from TCL. 3-Sulfopropyl acrylate potassium salt (SPA), $N$-methacryloyl chloride, 4-cyano-4-(phenylcarbonothioylthio)pentanoic acids, sodium citrate dihydrate and paraformaldehyde were purchased from Sigma-Aldrich. $\mathrm{N}$-Isopropylacrylamide (NIPAAm) was bought from Energy 
Scheme 1 Schematic diagram of AuNPs-pNMS promoting the neural differentiation of ESCs.

Chemical. Hydrogen tetrachloroaurate hydrate $\left(\mathrm{HAuCl}_{4} \cdot 4 \mathrm{H}_{2} \mathrm{O}\right)$ and fluorescein O-methacrylate (FluMA) were obtained from Sinopharm Chemical Reagent Co. (Shanghai, China) and Alfa Aesar Chemical Co., Ltd (China), respectively. Dulbecco's modified Eagle's medium (DMEM, high glucose), Roswell Park Memorial Institute (RPMI-1640) medium, 0.25\% (1×) trypsin, and $10 \times$ phosphate buffer solution (PBS) were purchased from Hyclone. Fetal bovine serum (FBS), non-essential amino acids (NEAA), and $0.1 \%$ Triton X-100 were obtained from Gibco. Leukemia inhibitory factor (LIF), bovine serum albumin (BSA), and $\beta$-mercaptoethanol were bought from Merck Millipore, Solarbio, and Beijing Dingguo Biotechnology Co. Ltd, respectively. Heparin $\left(M_{\mathrm{W}} \approx 3.5-8.0 \mathrm{kDa}\right), N, N$-dimethylformamide (DMF) and methyl alcohol were purchased from Shanghai Chemical Reagent Co. All aqueous solutions were prepared in purified water with a resistivity of $18.2 \mathrm{M} \Omega \mathrm{cm}$ (deionized water, DIW) from a Milli-Q water purification system (Millipore, Bedford, MA, USA).

\subsection{Synthesis of citrate-protected AuNPs}

Citrate-protected AuNPs were synthesized as previously reported. ${ }^{38}$ Briefly, all glass containers were soaked overnight in aqua regia solution $\left(\mathrm{HNO}_{3} / \mathrm{HCl}=1: 3, \mathrm{v} / \mathrm{v}\right)$ and washed with double-distilled water before use. A mixture of double-distilled water $(100 \mathrm{~mL})$ and $\mathrm{HAuCl}_{4}$ solution $(12 \mathrm{mM}, 516 \mu \mathrm{L})$ was taken in a $250 \mathrm{~mL}$ round-bottom flask equipped with a condenser and heated. When the solution in the flask started to boil, sodium citrate $(10 \% \mathrm{w} / \mathrm{v}, 4.4 \mathrm{~mL})$ was added into the mixture rapidly with vigorous stirring. The color changed from gray to red. The solution was boiled for another $15 \mathrm{~min}$ and then cooled down to room temperature.

\subsection{Synthesis of copolymers}

The 2-methacrylamido glucopyranose (MAG) monomer was synthesized as reported previously. ${ }^{28}$ The heparin mimic, pMS, was synthesized by reversible addition-fragmentation chain transfer (RAFT) polymerization as previously reported. ${ }^{28}$ Potassium 3-sulfonyl acrylate (SPA) and MAG were used as monomers ([SPA $]:[\mathrm{MAG}]=1: 1)$. 4-Cyano-4-(phenylcarbonothioylthio)pentanoic acid (CPADB) and AIBN were used as the chain transfer agent (CTA) and initiator (I), respectively. The monomers, CTA, and the initiator $([\mathrm{M}]:[\mathrm{CTA}]:[\mathrm{I}]=75: 2: 1)$ were dissolved in $5 \mathrm{~mL}$ of a mixed solvent (DMF:DIW $=1: 1, \mathrm{v} / \mathrm{v}$ ), which was bubbled with nitrogen for $30 \mathrm{~min}$ to remove oxygen in the container before being transferred into a glovebox for further reaction at $70{ }^{\circ} \mathrm{C}$ for $24 \mathrm{~h}$ (Fig. S1, ESI $\dagger$ ). The products were obtained via lyophilization after dialysis.

A series of thermosensitive pNMS heparin mimics were synthesized with $\mathrm{N}$-isopropylacrylamide as the monomer and pMS as the macromolecular chain transfer agent according to the above RAFT polymerization method. At the same time, according to the molecular weight of the thermosensitive heparin mimic, $\mathrm{pN}$ with the corresponding molecular weight is prepared (see Table S1, $\mathrm{ESI} \dagger)$. Information about the number-average molecular weights $\left(M_{w}\right)$ and polymer dispersity index (PDI) values of all copolymers was acquired by gel-permeation chromatography (GPC) experiments as shown in Table S2 (ESI $\dagger)$.

\subsection{Preparation of nanocomposites}

The copolymers $(0.5 \mathrm{~g})$ were dissolved in $1 \mathrm{~mL}$ of doubledistilled water in a glass round-bottom flask. Then, a sufficient amount of ethanolamine $(0.2 \mathrm{~mL})$ was added dropwise into the solution under stirring for $3 \mathrm{~h}$ to achieve thiol end groups of the polymers. The products were dialyzed against water for $48 \mathrm{~h}$ and then lyophilized. ${ }^{39}$ The obtained mercaptolated polymers were analyzed by UV-vis spectroscopy. AuNPs were centrifuged at $4{ }^{\circ} \mathrm{C}$ and $12000 \mathrm{rpm}$ (5810 R, Eppendorf) for $15 \mathrm{~min}$ to remove the supernatant. The mercaptolated polymers were dissolved in ultrapure water at a concentration of $0.5 \mathrm{mg} \mathrm{mL}^{-1}$ and used to resuspend the AuNPs. The mixture was incubated at $25{ }^{\circ} \mathrm{C}$ for $24 \mathrm{~h}$ to ensure the assembly of polymers on AuNPs. After the reaction, the supernatant was removed by centrifugation at $4{ }^{\circ} \mathrm{C}$ and $12000 \mathrm{rpm}^{38}$

\subsection{Cell culture and differentiation}

Mouse ESCs were seeded in a 96-well plate at a density of $6 \times 10^{3}$ for each well, which was coated with gelatin in the ESC medium overnight as mentioned above. After the treatment of the nanocomposites, the culture medium was replaced with fresh medium every other day. The cell viability was tested using a Cell Count 
Kit-8 (CCK-8) at days 1, 3 and 5. For L929 cells, the number of cells was $3 \times 10^{3}$ for each well. The treatment and CCK- 8 test were similar to those of mouse ESCs.

Primary generation ESCs were purchased from Shanghai Institutes for Biological Science, CAS. The cells were cultured in a T25 culture flask on the feeder layer under a humidified atmosphere in a $37{ }^{\circ} \mathrm{C}$ incubator (Eppendorf Galaxy $170 \mathrm{R}$ ) with $5 \%(\mathrm{v} / \mathrm{v}) \mathrm{CO}_{2}$. The feeder layers were mitomycin $\mathrm{C}$-inactivated mouse embryonic fibroblasts (MEF). ESCs were seeded at a density of $2 \times 10^{5}$ in each well of a 6-well plate that was coated with gelatin in the ESC medium overnight as mentioned above. Before the treatment of the nanocomposites, the cells were rinsed with PBS. Then, fresh medium suspended nanocomposites and the differentiation medium (DMEM high glucose medium containing 10\% FBS, 1\% penicillin/streptomycin, $100 \mathrm{U} \mathrm{mL}^{-1}$ plasmocin prophylactic, $0.1 \mathrm{mM}$ NEAA, and $0.1 \mathrm{mM} \beta$-mercaptoethanol) were added into the cell culture. The differentiation medium was changed every second day.

\subsection{Reverse transcription-polymerase chain reaction (RT-PCR) and real-time PCR}

Total RNAs were extracted from ESCs incubated in a sampleadded differentiation medium for $14 \mathrm{~d}$ using a total RNA Kit (Tiangen) following the manufacturer's instructions. RNAs were reverse-transcribed into cDNA using a RevertAid First Strand cDNA Synthesis Kit (Fermentas). The real-time PCR was carried on a Step One Plus real-time PCR system and marked by Fast SYBR Green Master Mix with a ROX reference dye (ABI). The cDNAs for the target genes, Oct-4, Sox17, Flk1, Nestin, and $\beta 3$-tubulin, were detected with $\beta$-actin as the reference gene (Table S3, ESI $\dagger$ ). Real-time PCR was performed with initial denaturation at $95{ }^{\circ} \mathrm{C}$ for $20 \mathrm{~s}$, followed by 50 cycles of $30 \mathrm{~s}$ denaturation at $95{ }^{\circ} \mathrm{C}, 45 \mathrm{~s}$ annealing at $60{ }^{\circ} \mathrm{C}$, and $45 \mathrm{~s}$ elongation at $72{ }^{\circ} \mathrm{C}$. The level of expression of target genes was calculated by using the $2^{-\Delta \Delta \mathrm{C}_{\mathrm{T}}}$ algorithm. All the samples were normalized to blank control group, which was set to 1 .

\subsection{Immunofluorescence assay}

Cells were fixed with $4 \%$ paraformaldehyde solution for $15 \mathrm{~min}$ and washed 3 times with PBS. Then, the cells were blocked with $3 \%$ BSA (in PBS) for 30 min and incubated with 1\% BSA (in PBS) containing the primary antibody against $\beta 3$-tubulin at $4{ }^{\circ} \mathrm{C}$ overnight. The primary antibody was removed and the cells were rinsed 3 times with PBS. The secondary antibody, goat anti-rabbit IgG H\&L (FITC), diluted in 1\% BSA, was added to the cells and incubated for $40 \mathrm{~min}$ at room temperature (RT). After rinsing, the nuclei of cells were stained with DAPI at room temperature for $5 \mathrm{~min}$. The representative pictures of the cells were taken by using a fluorescence microscope (Olympus IX71).

The cells were lysed and centrifuged at $4{ }^{\circ} \mathrm{C}$ and $12000 \mathrm{rpm}$ ( 5810 R, Eppendorf) for 15 min to remove the supernatant. The sediment was washed 3 times with PBS, then blocked with $3 \%$ BSA (in PBS) for $30 \mathrm{~min}$ and incubated with 1\% BSA (in PBS) containing the primary antibody against FGFR1 at $4{ }^{\circ} \mathrm{C}$ overnight. The primary antibody was removed and the sediment was rinsed 3 times with PBS. The secondary antibody, goat antirabbit IgG H\&L, diluted in 1\% BSA, was added to the cells and incubated for $40 \mathrm{~min}$ at room temperature (RT). After rinsing, the fluorescence intensity of the sediment was detected by using a microplate spectrophotometer.

\section{Results and discussion}

\subsection{Preparation and characterization of nanocomposites}

The random copolymer, pMS, was synthesized by RAFT polymerization using potassium 3-sulfonyl acrylate (SPA) and MAG as monomers. ${ }^{28}$ The obtained pMS was used as the macromolecular chain transfer agent for the synthesis of the blocking copolymer, pNMS. The exact structure of each copolymer can be further proved by the ${ }^{1} \mathrm{H}$ NMR spectra of the purified copolymers (Fig. S2-S4, ESI $\dagger$ ), from which the characteristic peaks of MAG, the sulfonated unit and NIPAAm are clearly visible. Their structural characteristics were detected using FTIR spectroscopy (Fig. 1). Since they all contained MAG and SPA, some characteristic peaks of functional groups correspondingly present in pMS and pNMS were in the same wavenumbers. Both copolymers displayed obviously a peak at around $3300 \mathrm{~cm}^{-1}$ which can be attributed to the $\mathrm{N}-\mathrm{H} / \mathrm{O}-\mathrm{H}$ bonds of MAG, and two peaks at $1665 \mathrm{~cm}^{-1}$ and $1530 \mathrm{~cm}^{-1}$, which can be assigned to the amide I band (mainly due to the $\mathrm{C}=\mathrm{O}$ stretching vibration) and the amide II band (a combination of the $\mathrm{N}-\mathrm{H}$ bending vibration and the $\mathrm{C}-\mathrm{N}$ stretching vibration) of MAG, respectively. The absorption peaks at around $1200 \mathrm{~cm}^{-1}$ and $1050 \mathrm{~cm}^{-1}$ in the two copolymers corresponded to the SO stretching from SPA. In comparison to pMS, pNMS displayed three specific peaks at $1465 \mathrm{~cm}^{-1}, 1385 \mathrm{~cm}^{-1}$ and $1368 \mathrm{~cm}^{-1}$, which can be attributed to the $\left(\mathrm{CH}_{3}\right)_{2} \mathrm{CH}$-bending vibration. The FTIR results indicated that both pMS and pNMS had MAG and SPA in their structures, and NIPAM was present only in the block copolymer pNMS.

The terminal groups of the polymer chain underwent sulfhydrylization by ethanolamine. According to the ultravioletvisible light absorption spectra before and after the sulfhydrylization of the polymer, the disappearance of the characteristic absorption peak at $304 \mathrm{~nm}$ for the dithioester in the copolymers could be observed after the sulfhydrylization (Fig. 2A). At low temperatures, polymer coils are extended and steric hindrance is relatively small. The achieved thiol end groups on the polymers offered a convenient way to graft the polymers on AuNPs because $\mathrm{Au}-\mathrm{S}$ can form easily and is very stable (Scheme 2). ${ }^{38,40,41}$ Since the conjugation of polymers would significantly increase the particle size of AuNPs, the hydrated diameters of these nanoparticles were investigated by dynamic light scattering (DLS). The results showed that the citrateprotected AuNPs had an average diameter of about $16 \mathrm{~nm}$, which was consistent with other reports. ${ }^{38}$ Compared with the unmodified AuNPs, the modification of polymers on AuNPs could obviously increase the hydrated diameters. As shown in Fig. 2B, there was an increase in the hydrated diameter of around $6 \mathrm{~nm}$ in AuNPs-pMS, which can be attributed to the polymer grafted on the surface of AuNPs, while the difference was more significant between AuNPs and AuNPs-pNMS, which 

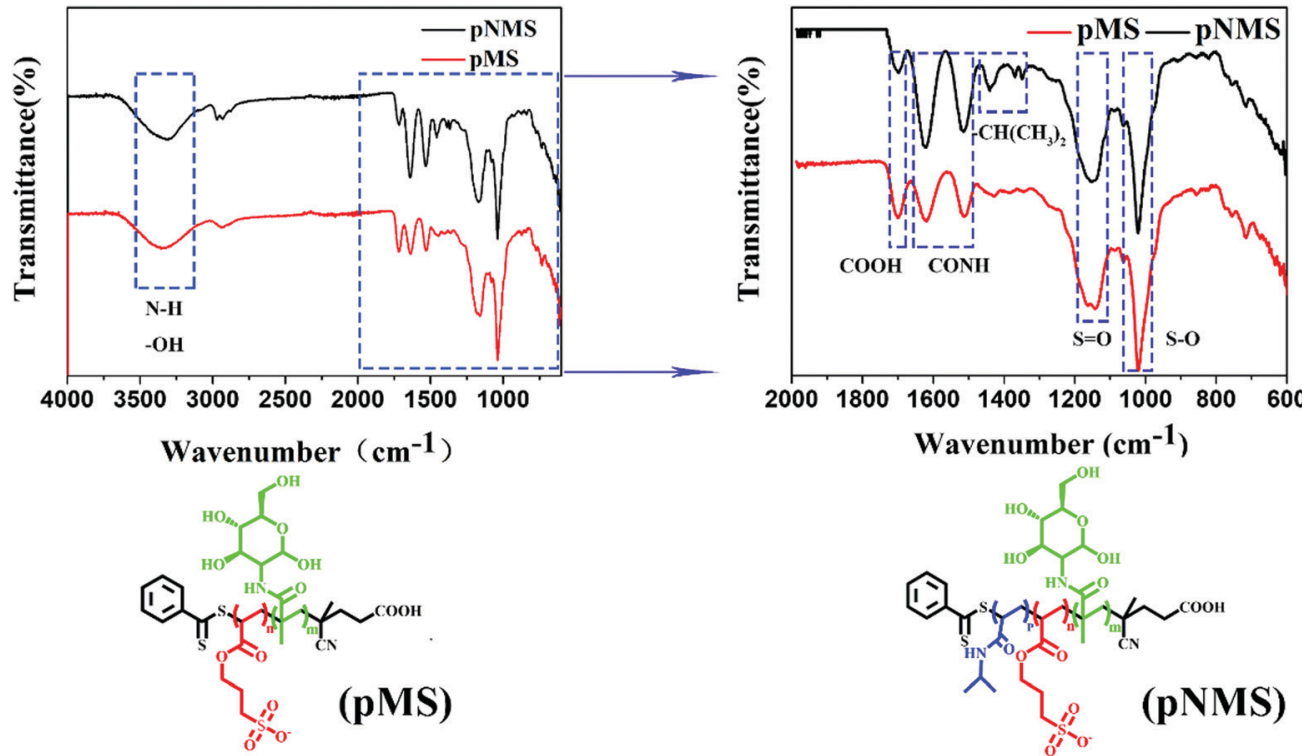

Fig. 1 Infrared spectra of the copolymers. PMS and pNMS are represented, respectively, as the random copolymer p(MAG-CO-SPA) and the block copolymer pNIPAAm-b-p(MAG-CO-SPA).
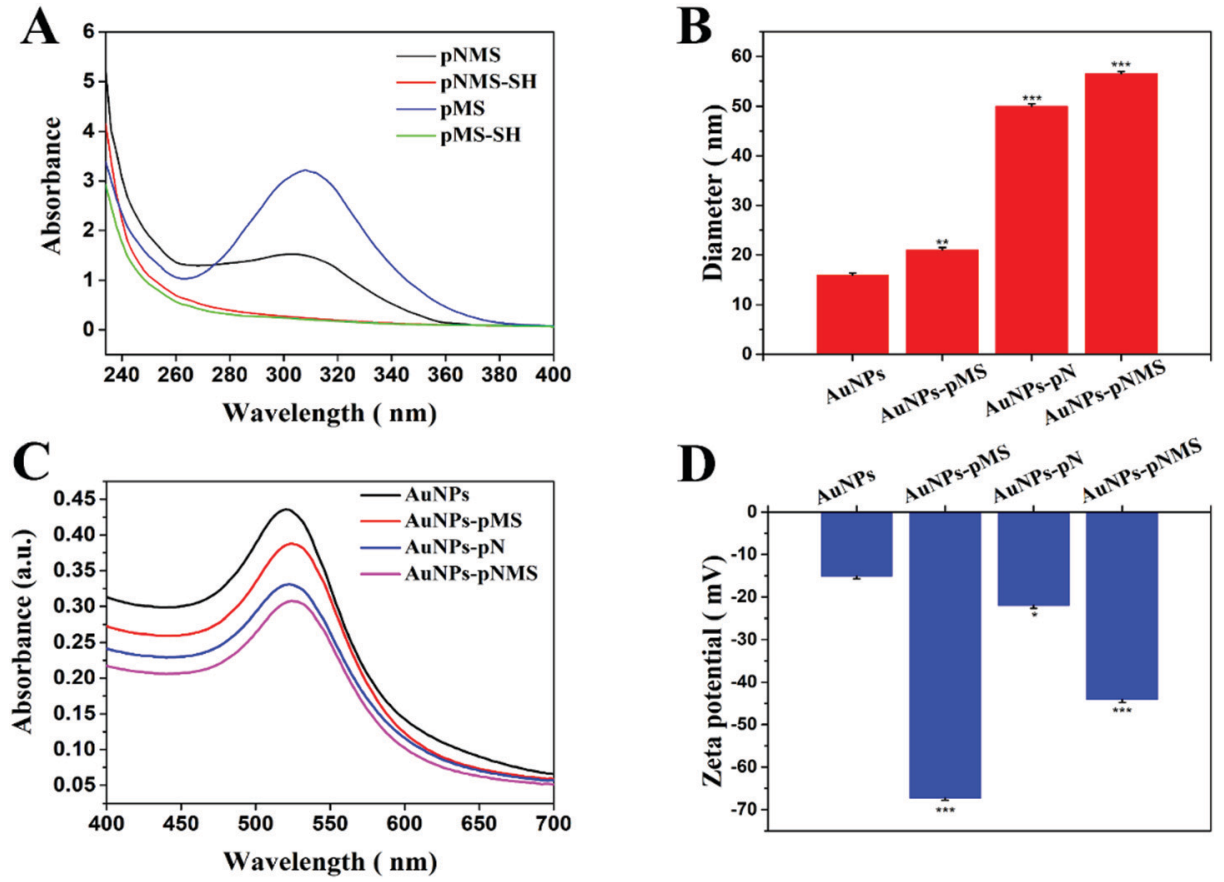

Fig. 2 Characterization of polymers and nanocomposites. (A) UV-Vis absorption spectra of the polymer before and after sulfhydrylization. (B) The hydrated diameters of nanoparticles. (C) Visible light absorption spectra of AuNPs and nanocomposites. (D) The zeta potential of AuNPs and nanocomposites. Data are presented as mean $\pm \mathrm{SD}(n=3),{ }^{*}, p<0.05 ; * *, p<0.01 ; * * *, p<0.001$ by $t$-test (AuNPs were the control group for the analysis of significant differences).

could be due to the longer polymer chain in pNMS than pMS. Considering that the specific SERS peak at $520 \mathrm{~nm}$ from AuNPs would always change after the conjugation of polymers, it was investigated by ultraviolet-visible spectroscopy. The spectra showed that the absorption peaks of AuNPs were visible at
$520 \mathrm{~nm}$ and several red-shifted absorption peaks at $524 \mathrm{~nm}$, $522 \mathrm{~nm}$ and $524 \mathrm{~nm}$, respectively, for AuNPs-pMS, AuNPs-pN and AuNPs-pNMS, corresponding to the polymer modifications (Fig. 2C). Meanwhile, the modification of polymers could also affect the surface potentials of the nanocomposites because of 
A
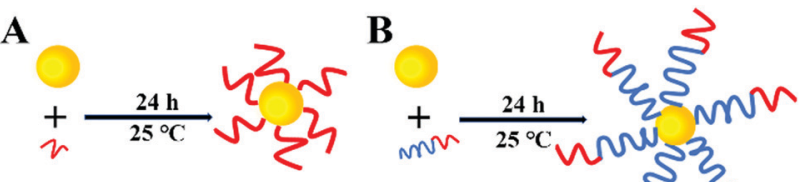

C

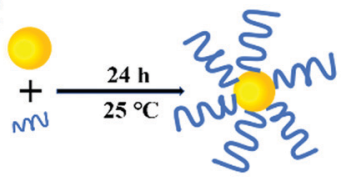

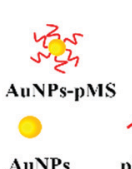

AuNPs pMS

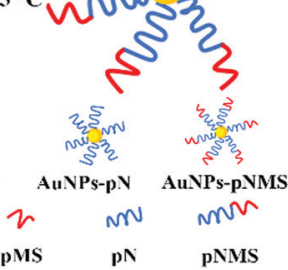

Scheme 2 Schematic diagram of the assembly of $\mathrm{SH}$-end group polymer and AuNPs. (A) Assembly of pMS and AuNPs, (B) assembly of pNMS and AuNPs, and (C) assembly of $\mathrm{pN}$ and AuNPs.

the negative charges on the sulfated groups in the side chains of the polymers (Fig. 2D). These results proved that the polymers could be well grafted onto AuNPs through Au-S bonds, forming different nanocomposites.

\subsection{Temperature responsiveness of nanocomposites}

There were two separated functional fragments in the copolymer pNMS. The fragment of pMS was a heparin mimic, responsible for the binding of FGF and FGFR and promoting neural differentiation. ${ }^{42}$ However, the fragment of $\mathrm{pN}$ was a polymer of NIPAAm, which was always applied as the temperature-sensitive polymer. ${ }^{43}$ The hydrated diameters of the AuNPs-pNMS were carefully investigated respectively at $25{ }^{\circ} \mathrm{C}$ and $37{ }^{\circ} \mathrm{C}$ by using DLS. As expected, the hydrated diameter of AuNPs-pNMS was almost $56 \mathrm{~nm}$ at $25^{\circ} \mathrm{C}$, while it decreased to as small as $40 \mathrm{~nm}$ at $37^{\circ} \mathrm{C}$ (Fig. 3A). However, the hydrated diameters of AuNPs-pMS at $25{ }^{\circ} \mathrm{C}$ and $37{ }^{\circ} \mathrm{C}$ showed no significant difference. This specific regulation of the hydrated diameter of AuNPs-pNMS at different temperatures could be attributed to the fragment of $\mathrm{pN}$ in the polymer chain. Although $\mathrm{pN}$ was close to the surface of AuNPs and covered by the pMS fragment, its excellent thermosensitivity could still lead to the hydrated diameter change of the nanocomposites. Meanwhile, the difference of the hydrated diameters of the nanocomposites at $25{ }^{\circ} \mathrm{C}$ and $37{ }^{\circ} \mathrm{C}$ had no obvious effect on their surface potentials (Fig. 3B). These results indicated that AuNPs-pNMS had a bigger hydrated diameter at $25{ }^{\circ} \mathrm{C}$, but a smaller one at $37{ }^{\circ} \mathrm{C}$, and the alteration of temperature did not change the dispersion or the surface potential of the nanocomposites. Considering that the hydrated diameter change would result in a change of the distances between the polymer chains located on AuNPs, the treatment of nanocomposites on the ESCs was mainly performed at $25{ }^{\circ} \mathrm{C}$ for $2 \mathrm{~h}$ and changed to $37{ }^{\circ} \mathrm{C}$ for cell culture and differentiation.

\subsection{The effect of nanocomposites on cell viability}

The nanocomposites were produced from AuNPs, pN, pMS and pNMS. It has been proved that AuNPs are biocompatible nanomaterials widely applied in clinical detection, imaging and therapy. ${ }^{44,45}$ In addition, both $\mathrm{pN}$ and pMS showed little toxic effect on cell growth, which offers them advantages in the studies of drug delivery, protein adsorption and cell
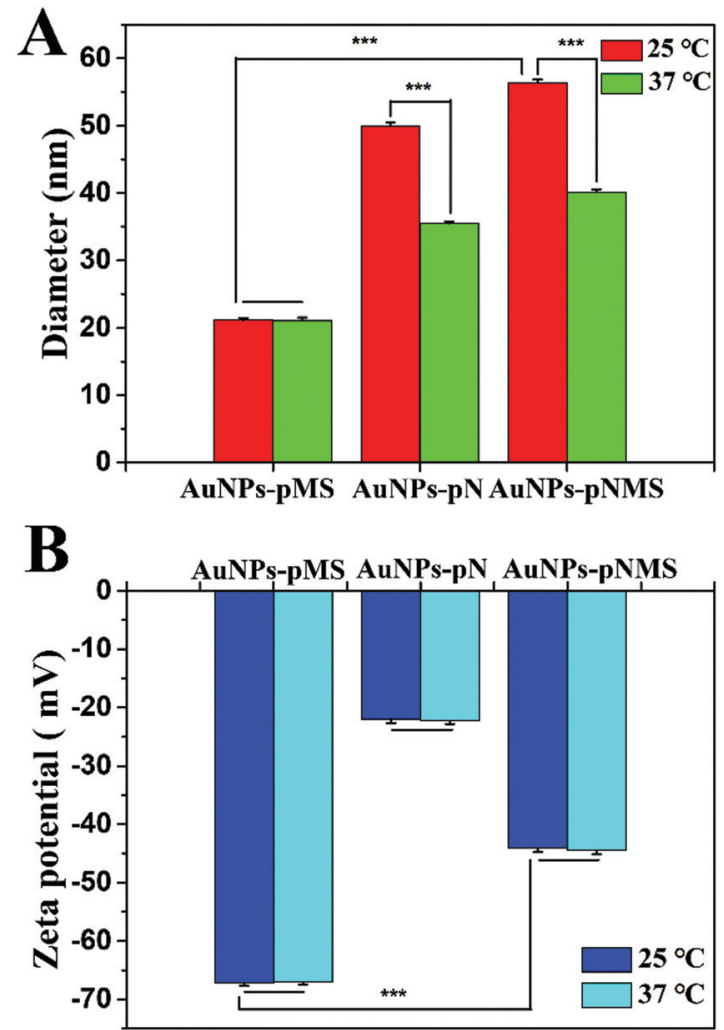

Fig. 3 Characterization temperature responsiveness of nanocomposites. (A) The hydrated diameters of nanocomposites at different temperatures. (B) The zeta potential of nanocomposites at different temperatures. Data are presented as mean $\pm \mathrm{SD}(n=3),{ }^{* * *}, p<0.001$ by $t$-test.

differentiation. ${ }^{28,46}$ In this study, the effects of the nanocomposites were investigated mainly on the growth and neural differentiation of ESCs. Compared with normal somatic cells, ESCs have potential abilities in the unlimited proliferation and pluripotent differentiation. However, they are more sensitive to the environment. Any improper condition can affect the growth of ESCs. Our results showed that all the nanocomposites of AuNPs-pMS, AuNPs-pN and AuNPs-pNMS exhibited the expected performance on the growth of ESCs (Fig. 4A). During the treatments within 5 days, there was just a small decrease, no more than $5 \%$, observed on the nanocomposite treated cells. The statistical analysis showed that these differences were not significant $(p>0.05)$, which suggests that no obvious cytotoxic effect on the growth of ESCs was observed after the treatment with nanocomposites. Similar phenomena were also observed on the treated L929 cells (Fig. 4B), which used as a cell model in evaluating the cytotoxic effect of biomaterials. These results indicated that AuNPs-pNMS had little cytotoxic effect on cell proliferation due to their desirable biocompatibility and could be then applied for neural differentiation.

\subsection{The effect of nanocomposites on the pluripotency of ESCs}

ESCs are undifferentiated cells that have self-renewal and pluripotent abilities. They were used to differentiate into all 


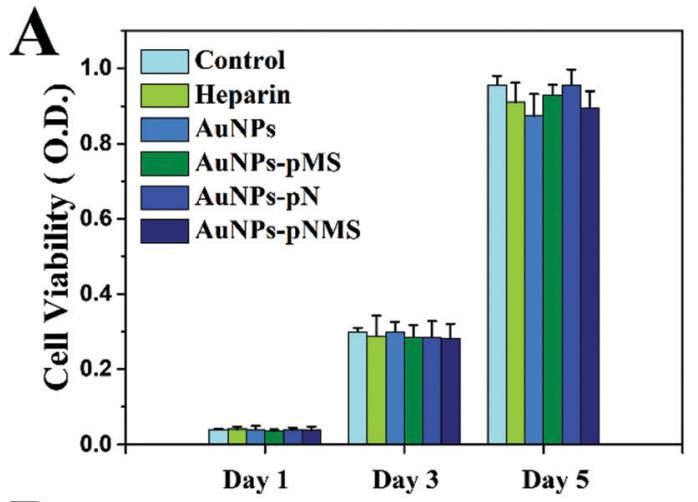

B

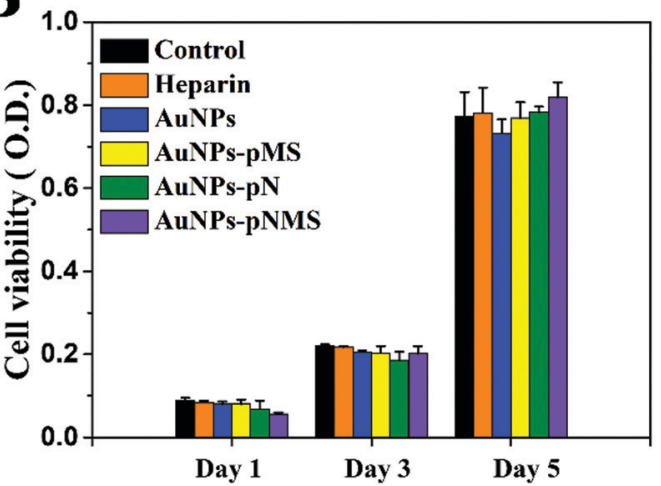

Fig. 4 Influence of nanocomposites and heparin on the proliferation of L929 and ESCs. (A) ESCs. (B) L929. Data are presented as mean \pm SD $(n=3)$.

types of functional cells for clinical studies. ${ }^{47}$ During the differentiation, there are many genes changing their expression levels. Among them, Oct-4, which is recognized as the specific marker for the pluripotency of ESCs, always shows decreased expression along with cell differentiation. The function of Oct-4 is to maintain the pluripotency of ESCs through its regulation in promoting the gene expression for pluripotency and preventing the gene expression for cell differentiation. Accordingly, a lower expression level of Oct-4 exists in the differentiated cells. Since the level of gene expression can be precisely detected by real-time PCR, the pluripotent state of ESCs was determined from Oct-4 expression in the cells after the treatment of different nanocomposites. As shown in Fig. 5A, it was obvious that the levels of Oct-4 expression in the cells treated with AuNPs-pMS and AuNPs-pNMS showed a considerable decrease at around 65\% compared with the negative control, while AuNP-treated ESCs maintained almost 65\% expression of $O c t-4$, which indicated that the decrease of Oct-4 expression by the treatment of nanocomposites might not result from AuNPs, but from the grafted copolymers. The suppression of Oct-4 expression by AuNPs-pMS had already been observed, which was due to the similarity of pMS with natural heparin. ${ }^{28}$ Meanwhile, the suppression of Oct-4 expression by AuNPs-pN had also been observed. Considering that $\mathrm{pMS}$ and $\mathrm{pN}$ served as one of the fragments in the block copolymer pNMS, the decrease of the Oct-4 expression level induced by AuNPs-pNMS was understandable. As a result of the suppression of Oct-4 expression, some cell differentiation events might have been initiated on ESCs.
Generally, there are three major directions initiating the differentiation of ESCs: endoderm, mesoderm and ectoderm. The expression level of the genes, Sox17, Flk1 and Nestin (representing the markers, respectively, for endoderm, mesoderm and ectoderm), were then detected on ESCs treated with different nanocomposites. ${ }^{48,49}$ It was shown that the expressions of Sox17 and Flk1 were inhibited to a great extent after the treatment with AuNPs-pMS, AuNPs-pN and AuNPs-pNMS for 14 days (Fig. 5B and C). AuNPs-pMS and AuNPs-pN could lead to the expression of $\operatorname{Sox} 17$ at a level of about $40 \%$ of the negative control, while AuNPs-pNMS treatment led to another 10\% decrease. AuNPs-pMS, AuNPs-pN and AuNPs-pNMS could lead to the expression of Flk1 at a level of about $30 \%$ of the negative control, especially AuNPs-pNMS, which showed better inhibition of Flk1 expression. The results suggested that neither endoderm nor mesoderm was the direction of differentiation for ESCs under the treatment of nanocomposites. However, the expression of the ectoderm marker, Nestin, had a totally different appearance. The transcribed Nestin in AuNPspMS and AuNPs-pN treated cells had reached 460\% and 480\% of the negative control, respectively (Fig. 5D). For AuNPs-pNMS treated cells, the level of Nestin even increased to more than $680 \%$ of the negative control. The results clearly demonstrated that the nanocomposites could promote the differentiation of ESCs, and the direction for the differentiation was close to the ectoderm.

\subsection{The effect of nanocomposites on the neural differentiation of ESCs}

In a previous report, the heparin mimic showed an promotion effect on the neural differentiation of ESCs, which was developed from the ectoderm. ${ }^{28}$ Considering the heparin mimic structures in the copolymers of pMS and pNMS, they would have a similar effect on neural differentiation. As shown in Fig. 6, the RT-PCR results showed that the nanocomposites could increase the expression of $\beta 3$-tubulin gene. The transcribed $\beta 3$-tubulin in AuNPs-pMS and AuNPs-pN treated cells had reached 35 times and 32 times that of the negative control, respectively. Holding the two fragments of $\mathrm{pN}$ and $\mathrm{pMS}$ together, AuNPs-pNMS exhibited a great promotion effect on $\beta 3$-tubulin expression, which was 91 times that of the negative control and 14 times that of the heparin group.

Correspondingly, as shown in Fig. 7D, there were some cellular structures like axons and dendrites formed in AuNPspMS treated cells. Since these structures are positively bound with anti- $\beta 3$-tubulin antibodies and show green fluorescence, it is suggested that the mature nerve cells could be effectively produced through the treatment. Similar structures were also observed in AuNPs-pNMS treated ESCs, but surprisingly in a high density and a broad area, which meant a much stronger effect of AuNPs-pNMS on promoting neural differentiation (Fig. 7F). The difference in structures between AuNPs-pMS and AuNPs-pNMS was just a fragment polymer $\mathrm{pN}$, which served as a linker in AuNPs-pNMS. Therefore, this phenomenon might be possibly caused by the elongation of the polymer chain to reach further FGFR on the cell membrane, or the 

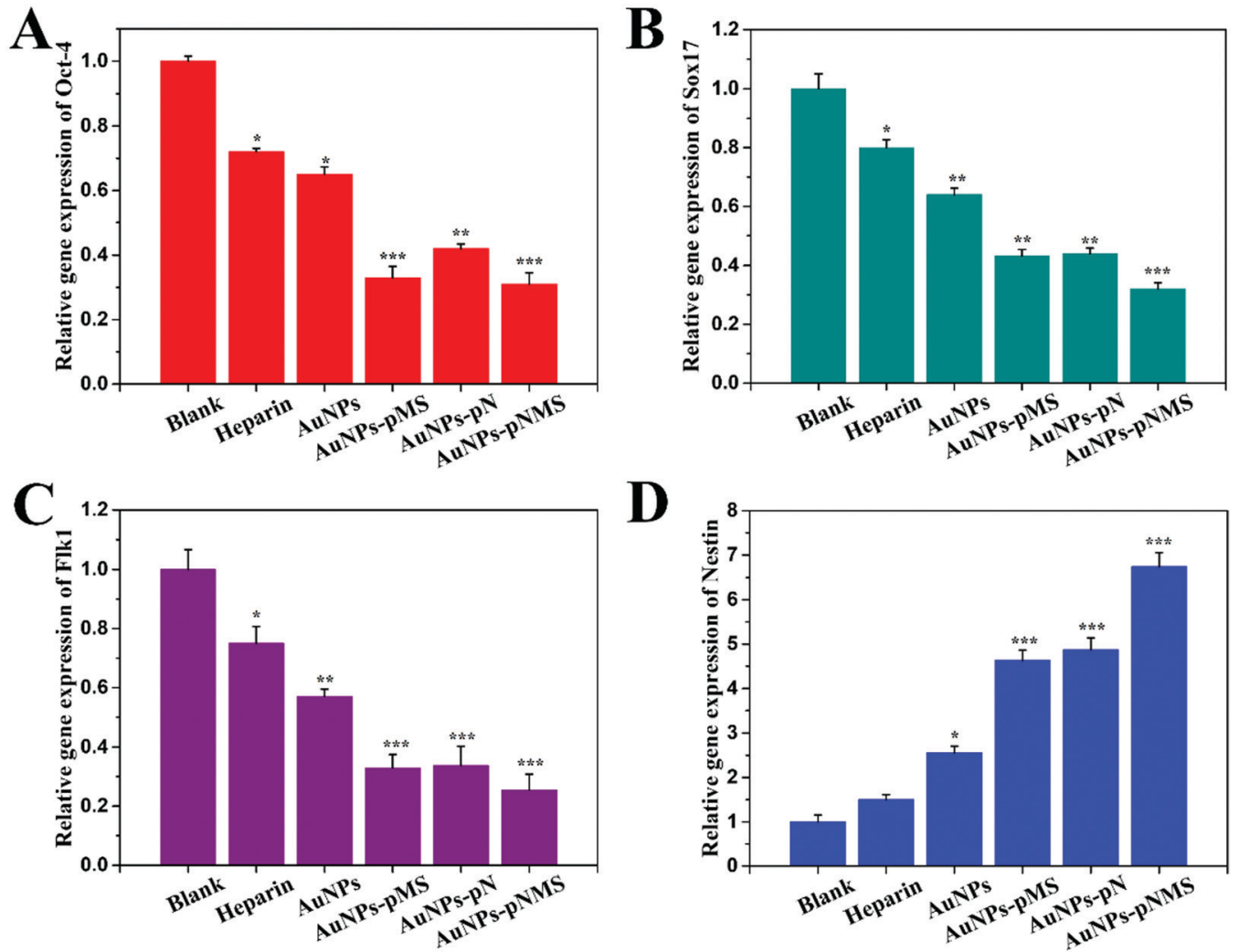

Fig. 5 Influence of heparin and nanocomposites on the relative expression levels of the pluripotency marker (Oct-4), the endoderm marker (Sox17), the mesoderm marker (Flk1) and the ectoderm marker (Nestin) in ESCs. ESCs were treated for 14 days. Data are presented as mean \pm SD ( $n=3)$, ${ }^{*}, p<0.05 ;{ }^{* *}, p<0.01 ;{ }^{* *}, p<0.001$ by $t$-test (blank was the negative control group for the analysis of significant differences).

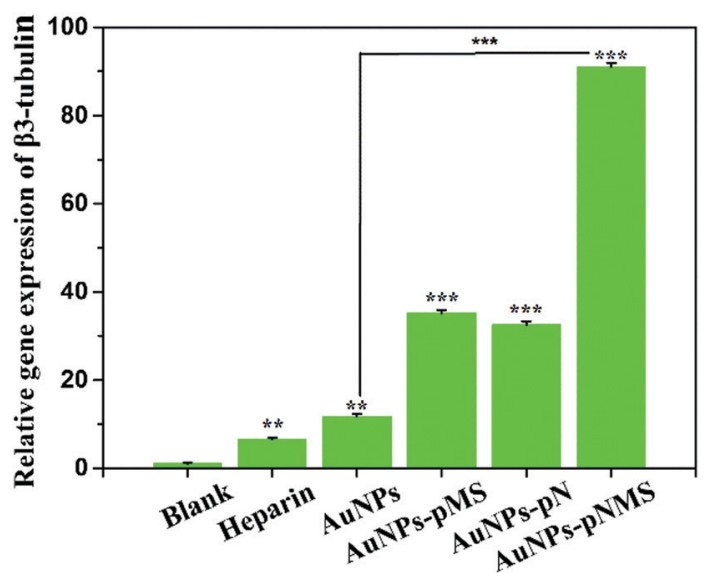

Fig. 6 Influence of heparin and nanocomposites on the relative expression levels of $\beta 3$-tubulin in ESCs. ESCs were treated for 14 days. Data are presented as mean $\pm \mathrm{SD}(n=3), * *, p<0.01 ; * * *, p<0.001$ by $t$-test (blank was the negative control group for the analysis of significant differences).

thermosensitivity of $\mathrm{pN}$ to regulate the hydrophilicity and length of the polymer chain, or the synergistic effect of the two segments, pN and pMS, in AuNPs-pNMS, greatly increases the efficiency of the nanocomposite binding to FGFR. The results showed that the temperature-sensitive nanocomposite
AuNPs-pNMS had a stronger effect on the differentiation of ESCs and can better promote the expression of $\beta 3$-tubulin and stimulate the synthesis of proteins required for neuronal maturation.

\subsection{The mechanism of nanocomposites on neural differentiation}

It was found that the optimal molecular weight of the heparin mimic glycopolymers for promoting neural differentiation was around $9 \times 10^{3} \mathrm{Da},{ }^{19,28}$ and longer polymer chains could not promote this effect much. Apparently, the elongation of the polymer chain by $\mathrm{pN}$ itself would not lead to a higher promotion effect of AuNPs-pNMS in neural differentiation, which was also proved in our study by using AuNPs-pMS with different pMS molecular weights.

By detecting the fluorescence intensity of FGFR, the efficiency of the combination of the nanocomposite and FGFR could be determined. As shown in Fig. 8, the fluorescence intensity of the cells treated by AuNPs-pMS, AuNPs-pN and AuNPs-pNMS was greatly increased compared with the heparin control. Among them, AuNPs-pNMS could promote the fluorescence intensity of the cells as high as 13.7 times that of heparin, which was twice that of AuNPs-pMS, while AuNPs maintained just 2.1 times that of heparin. The results indicated that the increase of the fluorescence intensity did not mainly come from AuNPs, but from pNMS grafted onto AuNPs, and this is mainly 

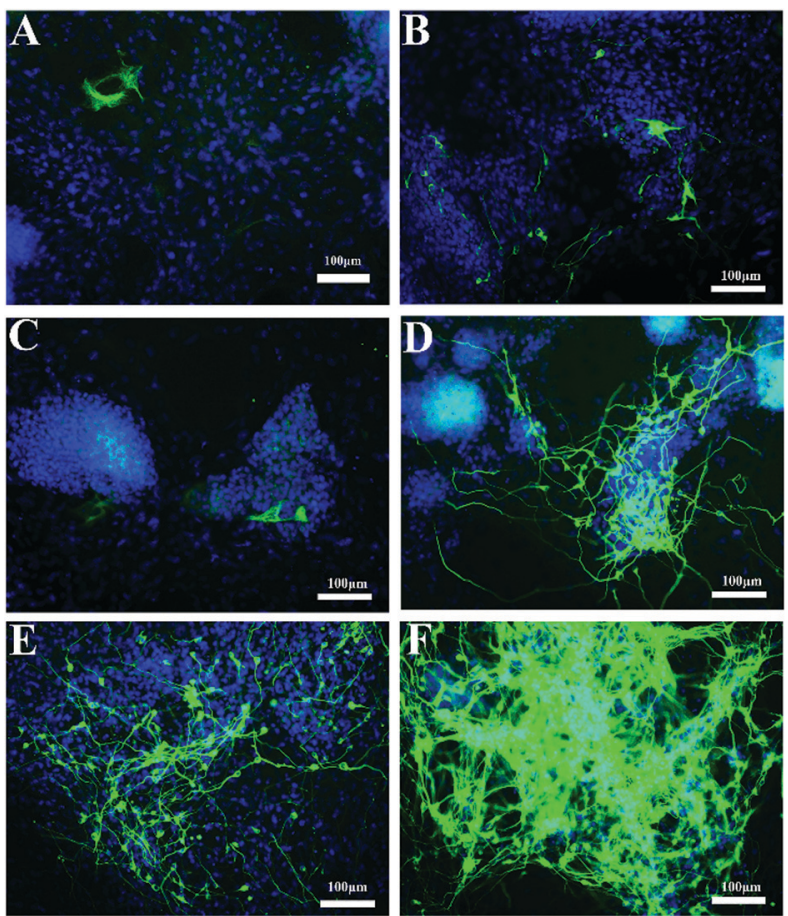

Fig. 7 Immunofluorescence images of the neural differentiation of ESCs for 14 days. (A) blank, (B) heparin, (C) AuNPs, (D) AuNPs-pMS, (E) AuNPs$\mathrm{pN}$, and (F) AuNPs-pNMS. Scale bar: $100 \mu \mathrm{m}$. $\beta 3$-Tubulin was detected with the anti- $\beta 3$-tubulin antibody (rabbit anti-mouse) and FITC-labeled goat anti-rabbit IgG (green), and cell nuclei were stained with DAPI (blue).

due to the pN fragment in the structure of AuNPs-pNMS. The effects of these nanocomposites show that the synergistic effect of $\mathrm{pN}$ and pMS in AuNPs-pNMS greatly increases the efficiency of the nanocomposite binding to FGFR, further enhancing the effect of the neural differentiation of ESCs.

Considering that the fragment of $\mathrm{pN}$ is covered under the fragment of pMS in AuNPs-pNMS and that pMS is a highly negatively-charged polyanion, it may not change the hydrophilicity

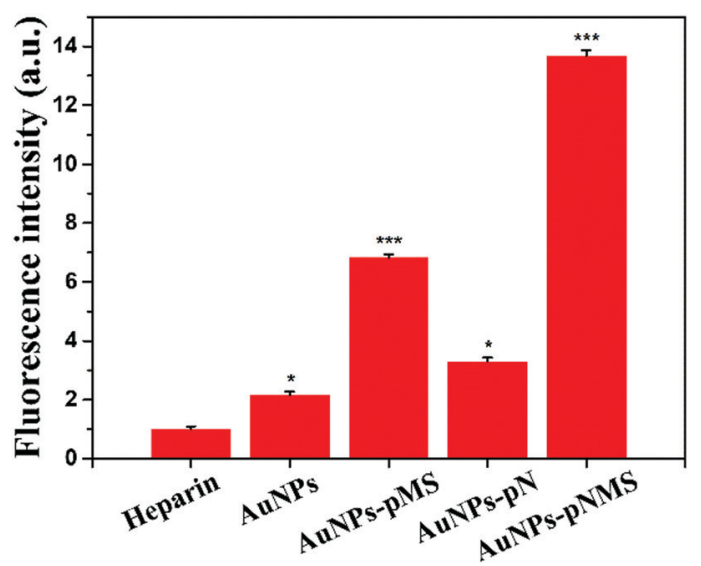

Fig. 8 The efficiency of heparin, AuNPs and nanocomposites binding to FGFR. Data are presented as mean $\pm \mathrm{SD}(n=3), *, p<0.05 ; * * *, p<0.001$ by $t$-test (heparin was the control group for the analysis of significant differences). of the nanocomposites much at $37{ }^{\circ} \mathrm{C}$. In order to determine the possible mechanism causing further increase of neural differentiation by AuNPs-pNMS, different MWs of $\mathrm{pN}$ were used as the linker to produce several AuNPs-pNMS, named AuNPs-pN1MS $\left(M_{\mathrm{n}}=13700 \mathrm{Da}\right)$, AuNPs-pN2MS ( $\left.M_{\mathrm{n}}=18500 \mathrm{Da}\right)$, AuNPs-pN3MS $\left(M_{\mathrm{n}}=28100 \mathrm{Da}\right)$ and AuNPs-pN4MS $\left(M_{\mathrm{n}}=37700 \mathrm{Da}\right)$. The results showed that, along with the increase of the $\mathrm{pN}$ MW, the hydrated diameters of the nanocomposites also increased due to the increase of the polymer chain length, and all nanocomposites showed good temperature sensitivity, which can be attributed to the $\mathrm{pN}$ fragment in the polymer chain (Fig. 9). Meanwhile, all four AuNPs-pNMS exerted an excellent promotion effect on neural differentiation (Fig. 10), while the expression levels of the mature neuronal protein marker $\beta 3$-tubulin in different AuNPs-pNMS treated ESCs were different. Since the MW of the pMS fragment was the same for AuNPs-pMS and all the AuNPs-pNMS, the difference in their biological effects should have been due to the lengths of $\mathrm{pN}$ in their structures. AuNPs-pN1MS, possessing the shortest $\mathrm{pN}$, showed a similar promotion effect on neural differentiation to AuNPs-pMS, which had no pN. For pNMS in the MW range of 13 700-28100 Dalton, the higher MW of $\mathrm{pN}$ resulted in a stronger promotion effect. The percentage of green fluorescence in AuNPs-pN3MS treated cells was as high as 75\% (Fig. 11B), and there were a large number of mature neuronal cells with the same axon and dendritic characteristics (Fig. 10C). However, for the largest one, AuNPs-pN4MS, the promotion effect decreased compared with AuNPs-pN3MS (Fig. 10 and 11). These results indicated that the length of $\mathrm{pN}$ in AuNPs-pNMS might play a key role in improving its biological effect. Owing to the thermosensitivity of pN, it could be assumed that AuNPs-pNMS could bind specifically with FGFR monomers on the cell membrane at $25{ }^{\circ} \mathrm{C}$, and, with the increase in temperature, the collapsed polymer chain would pull FGFR monomers together to form active FGFR dimers, which could initiate the signalling for neural differentiation (Scheme 1). To ensure this promotion effect, a proper length of $\mathrm{pN}$ is necessary. If it is too short, there is not enough space for the block copolymers to reach more separated FGFR monomers, while if it is too long, the

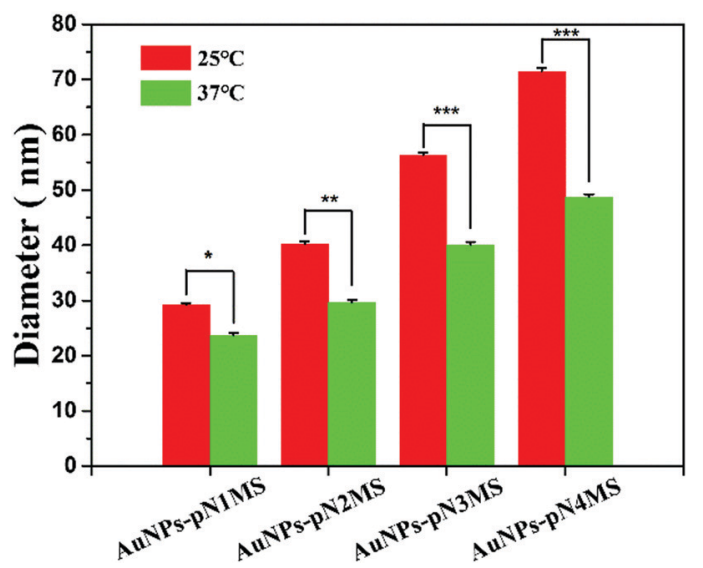

Fig. 9 The hydrated diameters of nanocomposites grafted with pNMS of different molecular weights. Data are presented as mean $\pm \mathrm{SD}(n=3)$, ${ }^{*}, p<0.05,{ }^{* *}, p<0.01$; ${ }^{* *}, p<0.001$ by $t$-test. 

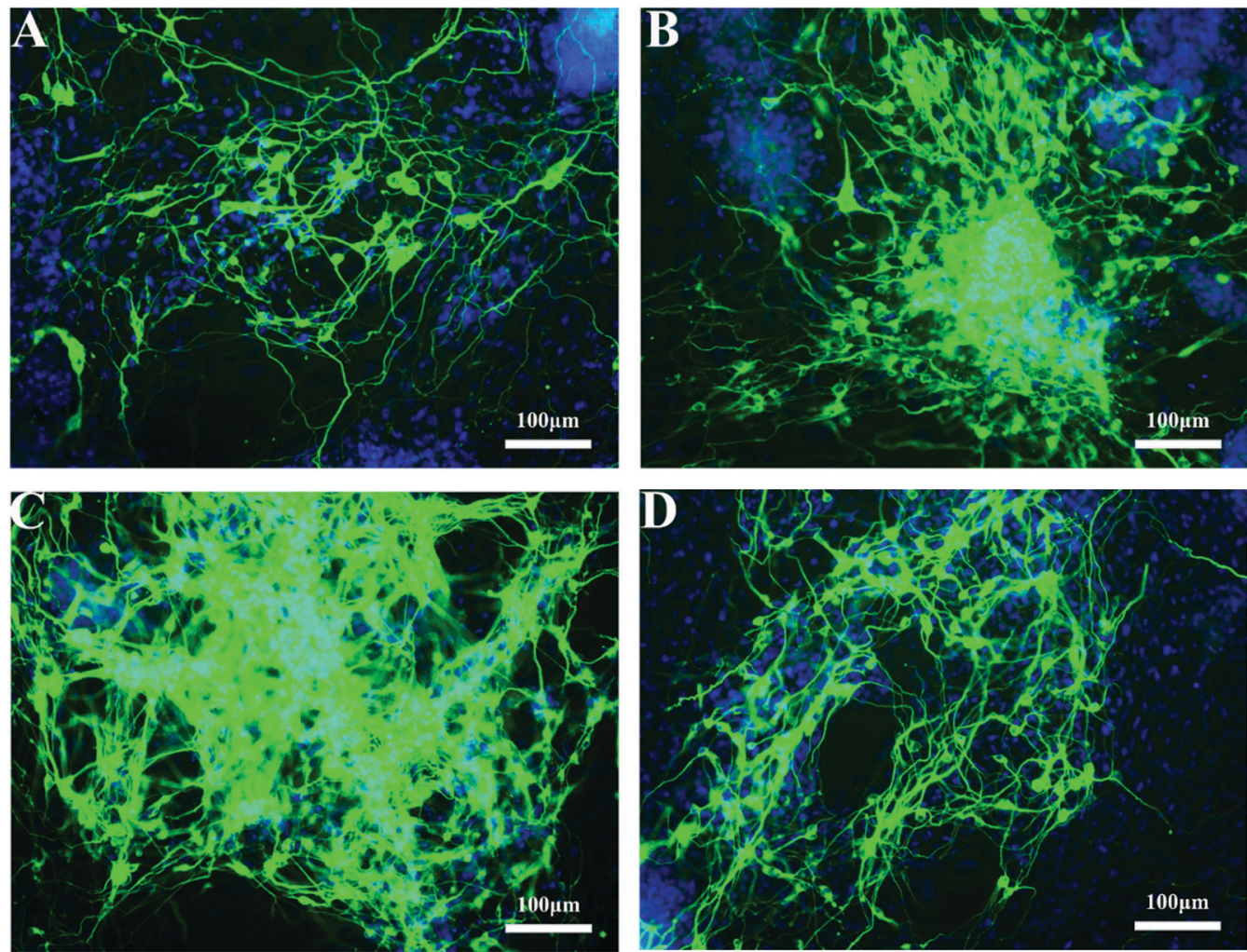

Fig. 10 Immunofluorescence images of ESCs treated with nanocomposites for 14 days. (A) AuNPs-pN1MS, (B) AuNPs-pN2MS, (C) AuNPs-pN3MS, and (D) AuNPs-pN4MS. Scale bar: $100 \mu \mathrm{m}$. $\beta 3$-Tubulin was detected with the anti- $\beta 3$-tubulin antibody (rabbit anti-mouse) and FITC-labeled goat anti-rabbit IgG (green), and cell nuclei were stained with DAPI (blue).

shrinkage of the polymer still leaves excess space and it is difficult to dimerize FGFR. As shown in our study, AuNPs-pN3MS might offer optimal regulation of the polymer length, leading to FGFR dimerization and then resulting in a desirable promotion effect on the neural differentiation of ESCs.

\section{Conclusion}

In summary, thermosensitive nanocomposites were prepared in this study to promote the neural differentiation of ESCs. The copolymer pMS, which served as the heparin mimic, is responsible for the specific binding of FGF and FGFR to the assembly
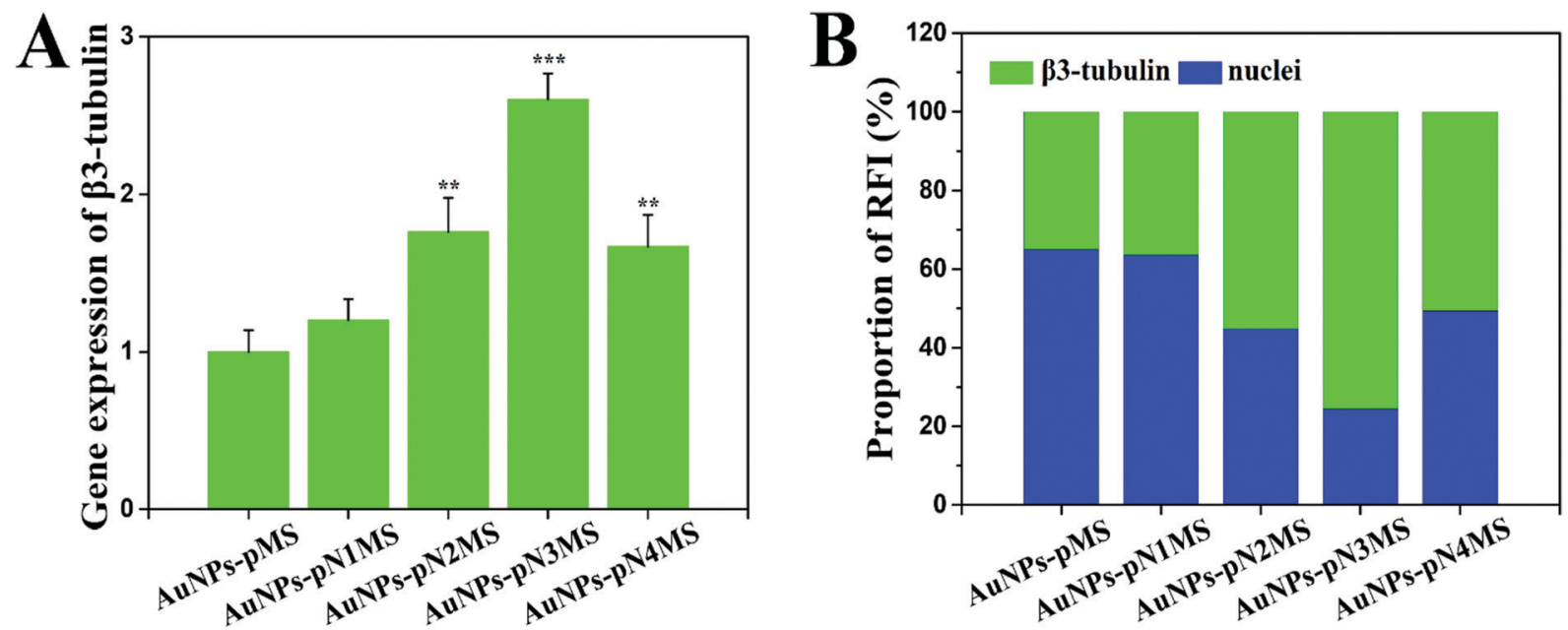

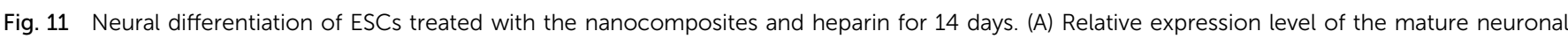

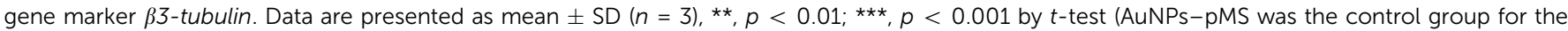

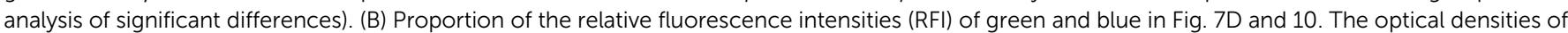
images in green and blue channels were measured using ImageJ software. 
of the pMS-FGF-FGFR mimicking complex. The fragment of pN, linking AuNPs and pMS, holds unique thermosensitive properties to extend the polymer chain at low temperature and collapse at high temperature, which provides proper space for the dimerization of FGFR. The synergistic effect of $\mathrm{pN}$ and $\mathrm{pMS}$ in AuNPs-pNMS greatly increases the efficiency of the nanocomposite binding to FGFR, while AuNPs can not only carry the functional polymers, but also increase the local amount of heparin mimics on the cell membrane. Combining all the above advantages, an excellent promotion effect on neural differentiation is achieved. This study presents a new strategy in increasing the dimerization of FGFR on the cell membrane and has great potential for cell differentiation.

\section{Conflicts of interest}

There are no conflicts to declare.

\section{Acknowledgements}

This work was supported by the National Natural Science Foundation of China (21774088), the Priority Academic Program Development of Jiangsu Higher Education Institutions (PAPD), and Jiangsu Clinical Research Center for Cardiovascular Surgery.

\section{Notes and references}

1 K. S. Zaret, Cell Stem Cell, 2009, 4, 373-374.

2 M. Dalziel, M. Crispin and R. A. Dwek, Proc. Natl. Acad. Sci. U. S. A., 2013, 110, 17608-17609.

3 Z. Lyu, X. Shi, J. Lei, Y. Yuan, L. Yuan, Q. Yu and H. Chen, J. Mater. Chem. B, 2017, 5, 1896-1900.

4 J. S. Lunn, S. A. Sakowski, J. Hur and E. L. Feldman, Ann. Neurol., 2011, 70, 353-361.

5 A. Kumar, K. Narayanan, R. K. Chaudhary, S. Mishra, S. Kumar, K. J. Vinoth, P. Padmanabhan and B. Gulyas, Mol. Neurobiol., 2017, 54, 7276-7296.

6 M. Ehrhart-Bornstein, K. F. Chung, V. Vukicevic and S. R. Bornstein, Mol. Psychiatry, 2009, 14, 2-4.

7 S. S. Kumar, A. A. Alarfaj, M. A. Munusamy, A. J. Singh, I. C. Peng, S. P. Priya, R. A. Hamat and A. Higuchi, Int. J. Mol. Sci., 2014, 15, 23418-23447.

8 A. Dierich, E. Le Guen, N. Messaddeq, J. F. Stoltz, P. Netter, P. Schaaf, J. C. Voegel and N. Benkirane-Jessel, Adv. Mater., 2007, 19, 693-697.

9 A. Higuchi, Q. D. Ling, S. S. Kumar, Y. Chang, A. A. Alarfaj, M. A. Munusamy, K. Murugan, S. T. Hsu and A. Umezawa, J. Mater. Chem. B, 2015, 3, 8032-8058.

10 S. M. Kang, M. S. Cho, H. Seo, C. J. Yoon, S. K. Oh, Y. M. Choi and D. W. Kim, Stem Cells, 2007, 25, 419-424.

11 C. Lund, K. Pulli, V. Yellapragada, P. Giacobini, K. Lundin, S. Vuoristo, T. Tuuri, P. Noisa and T. Raivio, Stem Cell Rep., 2016, 7, 149-157.
12 K. Ding, Y. Wang, H. Wang, L. Yuan, M. Tan, X. Shi, Z. Lyu, Y. Liu and H. Chen, ACS Appl. Mater. Interfaces, 2014, 6, 20043-20050.

13 S. J. Park, S. Kim, S. Y. Kim, N. L. Jeon, J. M. Song, C. Won and D. H. Min, ACS Appl. Mater. Interfaces, 2017, 9, 34634-34640.

14 R. Dai, Y. Hang, Q. Liu, S. Zhang, L. Wang, Y. Pan and H. Chen, J. Mater. Chem. B, 2019, 7, 4161-4168.

15 B. Thisse and C. Thisse, Dev. Biol., 2005, 287, 390-402.

16 F. Hu, B. Sun, P. Xu, Y. Zhu, X. H. Meng, G. J. Teng and Z. D. Xiao, Sci. Rep., 2017, 7, 39427.

17 S. Nishimoto and E. Nishida, J. Biol. Chem., 2007, 282, 24255-24261.

18 S. A. Sarkar and R. P. Sharma, Cell Biol. Toxicol., 2002, 18, 243-257.

19 M. Wang, Z. Lyu, G. Chen, H. Wang, Y. Yuan, K. Ding, Q. Yu, L. Yuan and H. Chen, Chem. Commun., 2015, 51, 15434-15437.

20 M. L. Huang, R. A. Smith, G. W. Trieger and K. Godula, J. Am. Chem. Soc., 2014, 136, 10565-10568.

21 Q. Liu, Z. Lyu, Y. Yu, Z. A. Zhao, S. Hu, L. Yuan, G. Chen and H. Chen, ACS Appl. Mater. Interfaces, 2017, 9, 11518-11527.

22 N. B. Schwartz and M. S. Domowicz, Adv. Neurobiol., 2014, 9, 89-115.

23 O. Yasa, O. Uysal, M. S. Ekiz, M. O. Guler and A. B. Tekinay, J. Mater. Chem. B, 2017, 5, 4890-4900.

24 R. K. Okolicsanyi, L. R. Griffiths and L. M. Haupt, Dev. Biol., 2014, 388, 1-10.

25 R. J. Holley, C. E. Pickford, G. Rushton, G. Lacaud, J. T. Gallagher, V. Kouskoff and C. L. R. Merry, J. Biol. Chem., 2011, 286, 6241-6252.

26 X. Lin, G. Wei, Z. Shi, L. Dryer, J. D. Esko, D. E. Wells and M. M. Matzuk, Dev. Biol., 2000, 224, 299-311.

27 T. Mikami and H. Kitagawa, Glycoconjugate J., 2017, 34, 725-735.

28 J. Lei, Y. Yuan, Z. Lyu, M. Wang, Q. Liu, H. Wang, L. Yuan and H. Chen, ACS Appl. Mater. Interfaces, 2017, 9, 28209-28221.

29 H. I. Seo, A.-N. Cho, J. Jang, D.-W. Kim, S.-W. Cho and B. G. Chung, Nanomedicine, 2015, 11, 1861-1869.

30 H. Kang, B. Yang, K. Zhang, Q. Pan, W. Yuan, G. Li and L. Bian, Nat. Commun., 2019, 10, 1696.

31 H. Kang, K. Zhang, H. J. Jung, B. Yang, X. Chen, Q. Pan, R. Li, X. Xu, G. Li, V. P. Dravid and L. Bian, Adv. Mater., 2018, 30, e1803591.

32 M. Wei, S. Li, Z. Yang, W. Zheng and W. Le, Nanomedicine, 2017, 12, 1305-1317.

33 S. Zhang, Y. Hang, J. Wu, Z. Tang, X. Li, S. Zhang, L. Wang, J. L. Brash and H. Chen, ACS Appl. Mater. Interfaces, 2020, 12, 22066-22073.

34 W. Cheng, L. Gu, W. Ren and Y. Liu, Mater. Sci. Eng., C, 2014, 45, 600-608.

35 E. J. Kim, S. H. Cho and S. H. Yuk, Biomaterials, 2001, 22, 2495-2499.

36 H. G. Schild, Prog. Polym. Sci., 1992, 17, 163-249.

37 Z. M. O. Rzaev, S. Dincer and E. Piskin, Prog. Polym. Sci., 2007, 32, 534-595. 
38 F. Liu, L. Wang, H. Wang, L. Yuan, J. Li, J. L. Brash and H. Chen, ACS Appl. Mater. Interfaces, 2015, 7, 3717-3724.

39 F. Yu, S. Cheng, J. Lei, Y. Hang, Q. Liu, H. Wang and L. Yuan, J. Biomater. Sci., Polym. Ed., 2020, 31, 1623-1647.

40 Y. Xue, X. Li, H. Li and W. Zhang, Nat. Commun., 2014, 5, 4348.

41 F. Liu, Y. C. Cui, L. Wang, H. W. Wang, Y. Q. Yuan, J. J. Pan, H. Chen and L. Yuan, ACS Appl. Mater. Interfaces, 2015, 7, 11547-11554.

42 J. Schlessinger, A. N. Plotnikov, O. A. Ibrahimi, A. V. Eliseenkova, B. K. Yeh, A. Yayon, R. J. Linhardt and M. Mohammadi, Mol. Cell, 2000, 6, 743-750.

43 Y. Ono and T. Shikata, J. Phys. Chem. B, 2007, 111, 1511-1513.
44 E. E. Connor, J. Mwamuka, A. Gole, C. J. Murphy and M. D. Wyatt, Small, 2005, 1, 325-327.

45 R. Shukla, V. Bansal, M. Chaudhary, A. Basu, R. R. Bhonde and M. Sastry, Langmuir, 2005, 21, 10644-10654.

46 S. Ohya and T. Matsuda, J. Biomater. Sci., Polym. Ed., 2005, 16, 809-827.

47 A. Rizzino, Wiley Interdiscip. Rev.: Syst. Biol. Med., 2009, 1, 228-236.

48 J. H. Lee, D. S. Lee, H. W. Choung, W. J. Shon, B. M. Seo, E. H. Lee, J. Y. Cho and J. C. Park, Biomaterials, 2011, 32, 9696-9706.

49 C. L. Mummery, J. Zhang, E. S. Ng, D. A. Elliott, A. G. Elefanty and T. J. Kamp, Circ. Res., 2012, 111, 344-358. 